\title{
Staged repair significantly reduces paraplegia rate after extensive thoracoabdominal aortic aneurysm repair
}

\author{
Christian D. Etz, MD, PhD, ${ }^{\mathrm{a}}$ Stefano Zoli, MD, ${ }^{\mathrm{a}}$ Christoph S. Mueller, MS, ${ }^{\mathrm{a}}$ Carol A. Bodian, DrPH, \\ Gabriele Di Luozzo, MD, ${ }^{a}$ Ricardo Lazala, MD, ${ }^{a}$ Konstadinos A. Plestis, MD, ${ }^{a}$ and Randall B. Griepp, MD $^{\mathrm{a}}$
}

Objective: Paraplegia remains a devastating, and still too frequent, complication after repair of extensive thoracoabdominal aortic aneurysms. Strategies to prevent ischemic spinal cord damage after extensive segmental artery sacrifice—or occlusion, essential for endovascular repair—are still evolving.

\begin{abstract}
Methods: Ninety patients who underwent extensive segmental artery sacrifice (median, 13; range, 9-15) during open surgical repair from June 1994 to December 2007 were reviewed retrospectively. Fifty-five patients (mean age, $65 \pm 12$ years; $49 \%$ were male), most with extensive Crawford type II thoracoabdominal aortic aneurysms, had a single procedure (single-stage group). Thirty-five patients (mean age, $62 \pm 14$ years; $57 \%$ were male) had 2 procedures (2-stage group), usually Crawford type III or IV repair after operation for Crawford type I descending thoracic aneurysm. The median interval between the 2 -stage procedures was 5 years ( 3 months to 17 years). There were no significant differences between the groups with regard to age, gender, cause of the aneurysm, hypertension, chronic obstructive pulmonary disease, urgency, previous cerebrovascular accidents, year of procedure, or cerebrospinal fluid drainage. In single-stage procedures, hypothermic circulatory arrest was used in $29 \%$ of patients, left-sided heart bypass was used in $40 \%$ of patients, and partial cardiopulmonary bypass was used in $27 \%$ of patients. Somatosensory-evoked potentials were monitored in all patients, and motor-evoked potentials were monitored in $39 \%$ of patients. Cerebrospinal fluid was drained in $84 \%$ of patients.
\end{abstract}

Results: Overall hospital mortality was $11.1 \%$. There were no significant differences in mortality, stroke, postoperative bleeding, infection, renal failure, or pulmonary insufficiency between the groups. However, $15 \%$ of patients in the single-stage group had permanent spinal cord injury versus none in the 2-stage group $(P=.02)$. The significantly lower rate of paraplegia and paraparesis in the 2 -stage group occurred despite a significantly higher number of segmental arteries sacrificed in this group: a median of 14 (11-15) versus 12 (9-15) $(P<.0001)$.

Conclusion: A staged approach to extensive thoracoabdominal aortic aneurysm repair may reduce the incidence of spinal cord injury. This is of particular importance in designing strategies involving hybrid or entirely endovascular procedures. (J Thorac Cardiovasc Surg 2010;139:1464-72)

Earn CME credits at

http://cme.ctsnetjournals.org

Surgery of the descending aorta has achieved remarkable success over the last 40 years. Aortic diseases that threaten catastrophic consequences, such as rupture or dissection, can now be treated with durable operations that have a low operative mortality. ${ }^{1-3}$ Paraplegia remains the most devastating

From the Departments of Cardiothoracic Surgery ${ }^{\mathrm{a}}$ and Anesthesiology, ${ }^{\mathrm{b}}$ Mount Sinai School of Medicine, New York, NY.

Disclosures: None.

Received for publication June 2, 2009; revisions received Jan 14, 2010; accepted for publication Feb 23, 2010.

Address for reprints: Christian D. Etz, MD, PhD, Mount Sinai School of Medicine, Department of Cardiothoracic Surgery, One Gustave L. Levy Place, PO Box 1028,

New York, NY 10029 (E-mail: christian.etz@mountsinai.org).

$0022-5223 / \$ 36.00$

Copyright $@ 2010$ by The American Association for Thoracic Surgery doi: $10.1016 /$ j.jtcvs. 2010.02 .037 complication after repair of extensive descending thoracic and thoracoabdominal aneurysms (TAA/A), whether by open surgical repair or endovascular strategies. ${ }^{4-7}$ A number of adjuncts have been successfully used intraoperatively and postoperatively to minimize both spinal cord ischemia during surgery and the consequences of a precarious spinal cord blood supply postoperatively, and the incidence of paraplegia and paraparesis at centers for aneurysm repair has been decreasing. ${ }^{3,8-15}$ Strategies to prevent ischemic spinal cord damage after extensive segmental artery (SA) sacrifice-or occlusion, essential for endovascular repairare still evolving.

The current retrospective study concerns 90 patients with extensive SA sacrifice ( $\geq 9$ SAs) during the course of aneurysm surgery, 55 of whom had a single-stage operation (Crawford II) and 35 of whom had a 2-stage operation. This study evaluates whether extensive SA loss in a 2-stage approach results in a decreased incidence of spinal cord injury compared with an equivalent SA loss in a single-stage approach. 


Abbreviations and Acronyms
CSF $=$ cerebrospinal fluid
HCA $=$ hypothermic circulatory arrest
MEP $=$ motor-evoked potential
SA $=$ segmental artery
SCP $=$ selective cerebral perfusion
SSEP $=$ somatosensory-evoked potential
TAA/A $=$ thoracic and thoracoabdominal aneurysm

\section{PATIENTS AND METHODS}

This study was a retrospective analysis of more than 600 open TAA/A repairs performed between June 1994 and December 2007, in which postoperative paraplegia or paraparesis developed in 23 patients (3.8\%). A total of 294 patients $(48 \%)$ underwent resection of a descending thoracic aneurysm, and 319 patients $(52 \%)$ required resection of a more extensive thoracoabdominal aortic aneurysm. This review disclosed 90 patients (patient demographics and clinical risk profiles, see Table 1) who had extensive SA sacrifice with no SA reimplantation during open surgical repair (average $12.8 \pm 1.3$; median, 13; range, 9-15; Figures 1 and 2). The institutional review board approved this research, and additional patient consent was not required.

\section{Operative Management}

All patients were placed in the standard thoracoabdominal position. A double-lumen endotracheal tube was used to isolate the left lung. A right radial arterial line, a right common femoral line, and a pulmonary artery catheter were inserted. Intraoperative transesophageal echocardiography was used in all patients. A spinal catheter was placed routinely, and cerebrospinal fluid (CSF) pressure was monitored during the operation and for the subsequent 72 hours; CSF was drained at a maximum rate of $15 \mathrm{~mL} / \mathrm{h}$ as long as CSF pressure remained above $10 \mathrm{~mm} \mathrm{Hg}$. Somatosensory-evoked potential (SSEP) and motor-evoked potential (MEP) monitoring (since 2002) have been used intraoperatively, and SSEP has been used for the first 12 hours postoperatively. 3,16

\section{Operative Technique}

The essential steps of our approach to the repair of descending thoracic and thoracoabdominal aortic aneurysms have been described. ${ }^{3,17}$ The aorta was accessed via a left thoracotomy or thoracoabdominal incision. The diaphragm was divided circumferentially. The infradiaphragmatic aorta was exposed through a retroperitoneal approach. All operations were carried out under moderate hypothermia $\left(32^{\circ} \mathrm{C}\right)$. If needed, deep hypothermia was used, with circulatory arrest initiated at a bladder temperature of $15^{\circ} \mathrm{C}$ and a jugular bulb cerebral venous saturation of $95 \%$ or more.

\section{Cannulation}

Arterial cannulation was usually via the femoral artery (74 patients, $82 \%$ ). A previously placed graft or the descending aorta was cannulated $(8 \%)$ in 7 patients, and the left axillary artery $(2 \%)$ was cannulated in 2 patients, as previously described by our group. ${ }^{18}$ Venous cannulation was usually performed by means of a wire-directed catheter placed through the femoral vein into the right atrium; in 1 patient the catheter could not be properly advanced, and direct cannulation of the inferior vena cava was performed. When left-sided heart bypass was used (30 patients, $33 \%$ ), the left atrium was cannulated directly $(\mathrm{N}=7)$ or via the inferior pulmonary vein $(\mathrm{N}=23)$.

\section{Hypothermic Circulatory Arrest}

Hypothermic circulatory arrest (HCA) $(\mathrm{N}=20)$ was effected by surface (cooling blanket) and perfusion cooling during the initial period
TABLE 1. Patient demographics and clinical risk profiles

\begin{tabular}{|c|c|c|c|c|}
\hline & $\begin{array}{c}\text { All } \\
\mathbf{N}=\mathbf{9 0}\end{array}$ & $\begin{array}{c}\text { Single-stage } \\
\text { procedure } \\
\mathbf{N}=\mathbf{5 5}\end{array}$ & $\begin{array}{c}\text { 2-stage } \\
\text { procedure } \\
\mathbf{N}=35\end{array}$ & $\begin{array}{c}P \\
\text { value* }\end{array}$ \\
\hline Male gender & $47(52 \%)$ & $27(49 \%)$ & $20(57 \%)$ & .52 \\
\hline Mean age \pm SD (y) & $64 \pm 13$ & $64 \pm 12$ & $62 \pm 14$ & .40 \\
\hline Age range (y) & $28-82$ & $28-80$ & $32-82$ & \\
\hline Patients aged $>60 y$ & $63(70 \%)$ & $42(76 \%)$ & $21(60 \%)$ & \\
\hline $\begin{array}{l}\text { Previous cardioaortic } \\
\text { procedures }\end{array}$ & $57(63 \%)$ & $22(40 \%)$ & $35(100 \%)$ & $<.0001$ \\
\hline $\begin{array}{l}\text { Urgent/emergency } \\
\text { operation }\end{array}$ & $23(26 \%)$ & $15(27 \%)$ & $8(23 \%)$ & .80 \\
\hline $\begin{array}{l}\text { Connective tissue } \\
\text { disorders }\end{array}$ & $11(12 \%)$ & $5(9 \%)$ & $6(17 \%)$ & .33 \\
\hline Marfan's syndrome & $8(9 \%)$ & $3(5 \%)$ & $5(14 \%)$ & \\
\hline Ehlers-Danlos syndrome & $3(3 \%)$ & $2(4 \%)$ & $1(3 \%)$ & \\
\hline COPD no. & $7(8 \%)$ & $5(9 \%)$ & $2(6 \%)$ & .70 \\
\hline Smoker & $43(48 \%)$ & $30(55 \%)$ & $13(37 \%)$ & .13 \\
\hline Coronary artery disease & $29(32 \%)$ & $19(35 \%)$ & $10(29 \%)$ & .65 \\
\hline $\begin{array}{l}\text { Previous myocardial } \\
\quad \text { infarction }\end{array}$ & $8(9 \%)$ & $7(13 \%)$ & $1(3 \%)$ & \\
\hline Requiring previous & $12(13.3 \%)$ & $6(11 \%)$ & $6(17.1 \%)$ & \\
\hline $\begin{array}{r}\text { CABG requiring } \\
\text { previous stent }\end{array}$ & $9(10 \%)$ & $6(10.9 \%)$ & $3(9 \%)$ & \\
\hline History of hypertension & $74(82 \%)$ & $44(80 \%)$ & $30(86 \%)$ & .58 \\
\hline IDDM & $8(9 \%)$ & $7(13 \%)$ & $1(3 \%)$ & .14 \\
\hline Renal insufficiency & $7(8 \%)$ & $5(9 \%)$ & $2(6 \%)$ & .70 \\
\hline Creatinine $\geq 1.6 \mathrm{mg} / \mathrm{dL}$ & $5(6 \%)$ & $5(9 \%)$ & - & \\
\hline Chronic hemodialysis & $2(2 \%)$ & - & $2(6 \%)$ & \\
\hline $\begin{array}{l}\text { Previous cerebrovascular } \\
\text { accident }\end{array}$ & $9(10 \%)$ & $7(13 \%)$ & $2(6 \%)$ & .47 \\
\hline Clot or atheroma & $19(21 \%)$ & $13(24 \%)$ & $6(17 \%)$ & .60 \\
\hline
\end{tabular}

$S D$, Standard deviation; $C O P D$, chronic obstructive pulmonary disease; $C A B G$, coronary artery bypass grafting; $I D D M$, insulin-dependent diabetes mellitus. *Based on the $t$ test or Fisher's exact test.

of cardiopulmonary bypass. Adequate cerebral cooling was ensured in all cases by cooling for a minimum of 30 minutes and maintaining a jugular venous saturation greater than $85 \%$ and an esophageal temperature of $12^{\circ} \mathrm{C}$ to $15^{\circ} \mathrm{C}$. In all patients in whom more than 20 minutes of HCA was anticipated or selective cerebral perfusion (SCP) was used, the head was packed circumferentially in ice.

Perfusion warming was carried out at the end of the procedure with the gradient between the esophageal and blood temperature maintained at less than $10^{\circ} \mathrm{C}$. Warming was maintained until esophageal temperature reached $35^{\circ} \mathrm{C}$ and bladder temperature was greater than $32^{\circ} \mathrm{C}$. Downward drift, however, resulted in most patients leaving the operating room with esophageal and bladder temperatures of $32^{\circ} \mathrm{C}$. Warming was usually accomplished in 1 hour of perfusion; during the last 15 or 20 minutes, partial bypass was frequently used to take advantage of improved warming with pulsatile perfusion. The average duration of cerebral ischemia was $30 \pm 7$ minutes at a mean minimum esophageal temperature of $12.6^{\circ} \mathrm{C} \pm 0.6^{\circ} \mathrm{C}$.

\section{Selective Cerebral/Upper-Body Perfusion}

Perfusion of all 3 head vessels and the coronary arteries was achieved with SCP at a blood temperature of $15^{\circ} \mathrm{C}$ to $20^{\circ} \mathrm{C}$ when cerebral protection time was expected to exceed 30 minutes. Flow was regulated to maintain a pressure of 50 to $60 \mathrm{~mm} \mathrm{Hg}$, which usually required a flow of 1000 to 


\section{Extent of Segmental Artery Sacrifice in Each Patient}

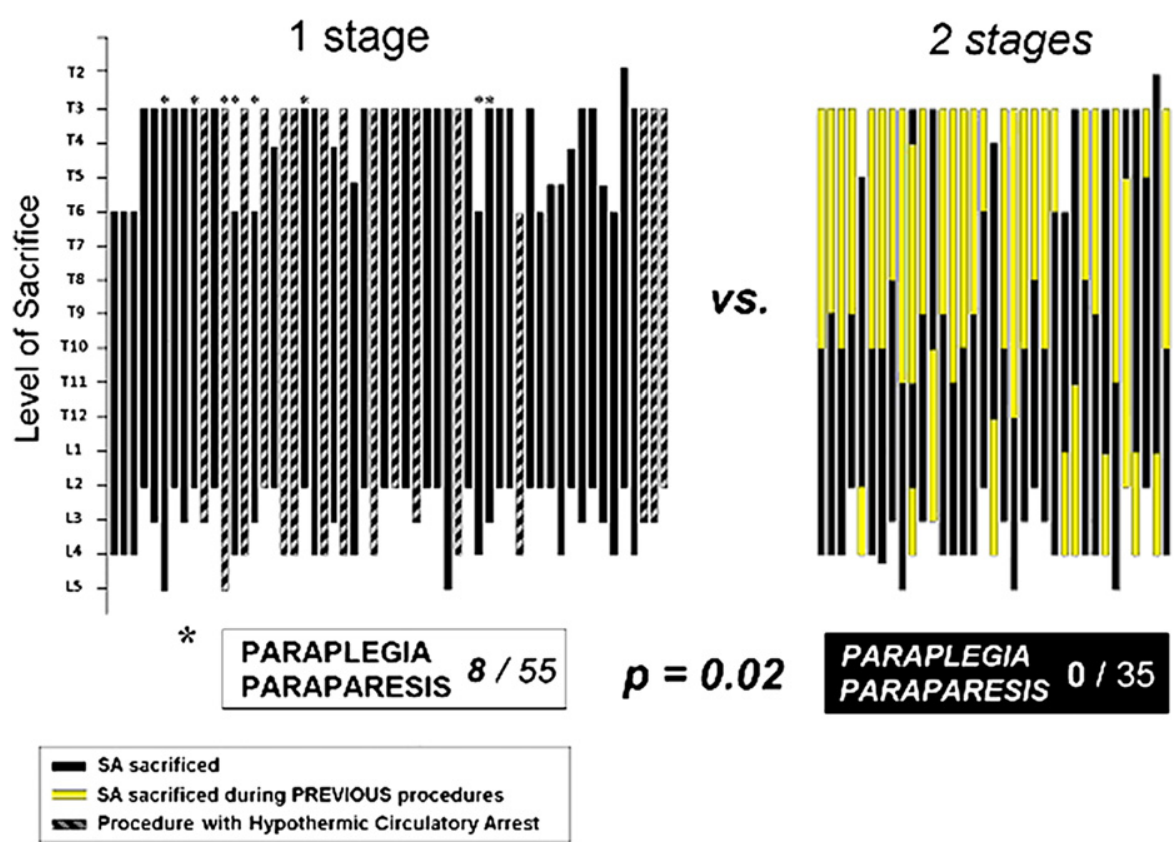

FIGURE 1. Extent of SA sacrifice in each patient. Patients were divided into 2 groups according to the number of procedures $(1$ stage: $\mathrm{N}=55 ; 2$ stages: $\mathrm{N}=35$ ). The extent of SA sacrifice during previous procedures is represented by the yellow part of each bar. Patients with postoperative spinal cord injury (*). One-stage procedures with HCA (hatched bars). Paraparesis developed in only 1 patient when HCA was used. SA, Segmental artery.

$1500 \mathrm{~mL} / \mathrm{min}$. Seventeen patients required upper-body perfusion for an average of $42 \pm 28$ minutes. The left ventricle was vented via the apex. SCP can be established either by left axillary cannulation or using the proximal graft with a side branch. Partial cardiopulmonary bypass is combined with beating heart upper-body perfusion.

\section{Extent of Operation}

More than $95 \%$ of all patients had visceral artery reimplantation $(\mathrm{N}=86)$. The celiac trunk was reimplanted in 83 patients, the renal arteries were reimplanted in 82 patients, and the superior mesenteric artery was reimplanted in 86 patients. Intraoperative details are shown in Table 2.

\section{Number of patients with each number of SA sacrificed \\ Single Stage and Staged Procedures $(N=90)$}

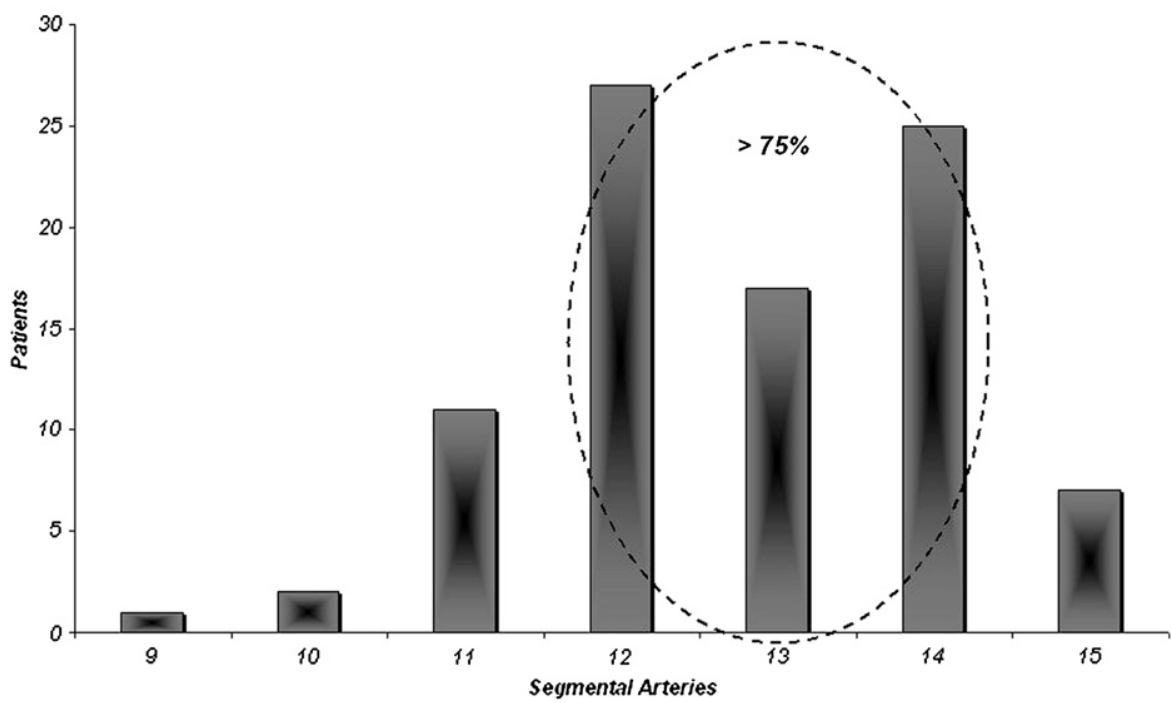

FIGURE 2. The number of patients in the entire cohort $(\mathrm{N}=90)$ with each number of segmental arteries sacrificed. Note that more than $75 \%$ of patients required sacrifice of 12,13 , or 14 segmental arteries. 
TABLE 2. Intraoperative details

\begin{tabular}{|c|c|c|c|c|}
\hline & $\begin{array}{c}\text { All } \\
\mathbf{N}=\mathbf{9 0}\end{array}$ & $\begin{array}{c}\text { Single-stage } \\
\text { procedure } \\
\mathbf{N}=\mathbf{5 5} \\
\end{array}$ & $\begin{array}{c}2 \text {-stage } \\
\text { procedure } \\
\mathbf{N}=\mathbf{3 5}\end{array}$ & $\begin{array}{c}P \\
\text { value }\end{array}$ \\
\hline \multicolumn{5}{|l|}{ Cause } \\
\hline Atherosclerosis & $47(52 \%)$ & $31(56 \%)$ & $16(46 \%)$ & .35 \\
\hline Dissection & $30(33 \%)$ & $15(27 \%)$ & $15(43 \%)$ & \\
\hline Degenerative & $9(10 \%)$ & $7(13 \%)$ & $2(6 \%)$ & \\
\hline Other & $4(4 \%)$ & $2(4 \%)$ & $2(6 \%)$ & \\
\hline \multicolumn{5}{|c|}{ Descending aortic diameter $(\mathrm{cm})$} \\
\hline Mean $\pm \mathrm{SD}$ & $6.6 \pm 1.2$ & $6.6 \pm 1.3$ & $6.5 \pm 1.0$ & .78 \\
\hline Median (range) & $6.5(4.4-12)$ & $6.5(4.4-12)$ & $6.4(5.2-9)$ & .68 \\
\hline $\begin{array}{l}\text { Elephant trunk completion } \\
\text { (second stage) }\end{array}$ & $14(16 \%)$ & $11(20 \%)$ & $3(9 \%)$ & .23 \\
\hline \multicolumn{5}{|l|}{ Aortic graft } \\
\hline Size $(\mathrm{mm})$ & $24.2 \pm 3$ & $24.2 \pm 3$ & $24.1 \pm 3.8$ & .79 \\
\hline Median (range) & $24(14-34)$ & $24(18-28)$ & $24(14-34)$ & .50 \\
\hline \multicolumn{5}{|c|}{ Reimplanted visceral arteries (no. of patients) } \\
\hline Celiac & $83(92 \%)$ & $52(95 \%)$ & $31(89 \%)$ & .42 \\
\hline Superior mesenteric & $86(96 \%)$ & $54(98 \%)$ & $32(91 \%)$ & .29 \\
\hline Renal & $82(90 \%)$ & $53(96 \%)$ & $29(83 \%)$ & .05 \\
\hline Intercostal/lumbar & - & & - & \\
\hline SSEP monitoring & $90(100 \%)$ & $55(100 \%)$ & $35(100 \%)$ & 1 \\
\hline MEP monitoring & $35(39 \%)$ & $21(38 \%)$ & $14(40 \%)$ & 1 \\
\hline CSF drainage & $76(84 \%)$ & $47(86 \%)$ & $29(83 \%)$ & .77 \\
\hline Perfusion strategy & & & & .01 \\
\hline None & $7(8 \%)$ & $2(4 \%)$ & $5(14 \%)$ & \\
\hline PCBP & $33(37 \%)$ & $15(27 \%)$ & $18(51 \%)$ & .45 \\
\hline PLHB & $30(33 \%)$ & $22(40 \%)$ & $8(23 \%)$ & .07 \\
\hline $\mathrm{HCA}$ & $20(22 \%)$ & $16(29 \%)$ & $4(11 \%)$ & .58 \\
\hline $\begin{array}{l}\text { Cerebral ischemia } \\
\text { time ( } \mathrm{min})\end{array}$ & $30 \pm 7$ & $29 \pm 7$ & $33 \pm 6$ & .43 \\
\hline SCP time $\dagger$ (min) & $42 \pm 28$ & $49 \pm 28$ & $22 \pm 13$ & \\
\hline $\begin{array}{l}\text { Lowest esophageal } \\
\text { temperature }\left({ }^{\circ} \mathrm{C}\right)\end{array}$ & $12.6 \pm 1.6$ & $12.6 \pm 1.7$ & $12.8 \pm 1.2$ & \\
\hline $\begin{array}{l}\text { Lowest bladder } \\
\text { temperature }\left({ }^{\circ} \mathrm{C}\right)\end{array}$ & $17.5 \pm 3.7$ & $17.2 \pm 3.7$ & $19 \pm 4.7$ & \\
\hline $\begin{array}{l}\text { Visceral perfusion (cold } \\
\text { blood, no. of patients) }\end{array}$ & $29(32 \%)$ & $14(25 \%)$ & $15(43 \%)$ & .11 \\
\hline $\begin{array}{l}\text { Segmental arteries } \\
\text { sacrificed (n) }\end{array}$ & & & & $<.0$ \\
\hline Overall $($ mean $\pm \mathrm{SD})$ & $12.8 \pm 1.3$ & $12.3 \pm 1.3$ & $13.5 \pm 1$ & \\
\hline $\begin{array}{l}\text { First procedure } \\
\qquad(\text { mean } \pm \mathrm{SD})\end{array}$ & & & $6.5 \pm 2.2$ & \\
\hline $\begin{array}{l}\text { Second procedure } \\
\quad(\text { mean } \pm \mathrm{SD})\end{array}$ & & & $7 \pm 2.1$ & \\
\hline
\end{tabular}

$S C P$, Selective cerebral perfusion; SSEP, somatosensory-evoked potentials; $M E P$, motor-evoked potentials; $C S F$, cerebrospinal fluid; $H C A$, hypothermic circulatory arrest; $P L H B$, partial left-sided heart bypass; $S D$, standard deviation. *Based on the chisquare, $t$, and Kruskal-Wallis tests. †SCP used in 17 patients. Two-stage data reflect only the second of the 2-stage procedures.

The preferred technique for reimplantation was via an additional side arm in the main graft $(\mathrm{N}=121,48 \%)$ followed by a long beveled anastomosis including the orifices of the visceral vessels $(\mathrm{N}=83,33 \%)$. Twentyeight visceral arteries $(11 \%)$ were reimplanted singly with a button technique, and 19 visceral arteries $(8 \%)$ were reimplanted using a Carrel patch.

\section{Single-Stage Group}

Fifty-five patients, most with extensive Crawford type II TAA-A, had a single procedure (single-stage group). The mean age was $64 \pm 12$ years, $27(49 \%)$ were male, and the most common cause was atherosclerosis $(\mathrm{N}=31,56 \%)$. Twenty-two patients $(40 \%)$ had undergone previous cardioaortic procedures not involving the descending or abdominal aorta. A total of 27 previous procedures were performed: 4 ascending aortic aneurysm repairs, 5 coronary artery bypass grafts, 3 Bentall procedures, 14 complete arch repairs (5 as the first stage of an elephant trunk procedure), and 1 axillo-bifemoral bypass. In these single-stage procedures, HCA was used in 16 patients $(29 \%)$, left-sided heart bypass was used in 22 patients $(40 \%)$, and partial cardiopulmonary bypass was used in 15 patients $(27 \%)$; only 2 patients $(4 \%)$ underwent resection with a clamp-and-sew technique. Demographics and clinical risk profiles are summarized in Table 1, and intraoperative characteristics are shown in Table 2.

\section{Two-Stage Group}

Thirty-five patients had extensive aortic resection in the course of 2 operations (2-stage group). The 2-stage approach in these patients was not a deliberate strategy but rather the consequence of aneurysms in different parts of the aorta developing at different rates or different times. The most common pattern was repair of a Crawford type III or IV aneurysm after operation for a descending thoracic aneurysm or Crawford type I lesion. The mean age of this cohort of patients was $62 \pm 14$ years at the time of second operation, and $20(57 \%)$ were male. The median interval between the 2 -stage procedures was 5 years ( 3 months to 17 years). For the second stage, HCA was used in 4 patients (11\%), left-sided heart bypass was used in 8 patients $(23 \%)$, and partial cardiopulmonary bypass was used in 18 patients $(51 \%) ; 5$ patients $(14 \%)$ underwent repair with the clamp-and-sew technique.

Details regarding the initial procedures were unavailable in some of the few patients whose first operations had been performed in other institutions. An average of $6.5 \pm 2.2 \mathrm{SAs}$ (median, 7; range, 3-10) were sacrificed during the first operation, and $7 \pm 2.1$ SAs (median, 6; range, 3-12) were sacrificed during the second procedure (Figure 3 ).

\section{Postoperative Management}

Aggressive fluid administration for at least the first 24 postoperative hours was initiated, aiming for a mean aortic pressure of 80 to $90 \mathrm{~mm}$ $\mathrm{Hg}$, with vasoconstrictors (usually vasopressin and norepinephrine) given as necessary to maintain this pressure. Gentle diuresis was begun 48 to 72 hours after operation. SSEPs were monitored until the patient awakened. Thereafter, hourly brief neurologic examinations were performed for 72 hours. CSF drainage (as previously noted) was continued for 72 hours. Steroids were tapered over 48 to 72 hours.

\section{Statistical Methods}

Data were entered in an Excel spreadsheet (Microsoft Corp, Redmond, Wash) and transferred to a SAS file (SAS Institute Inc, Cary, NC) for data description and analysis. Patient characteristics are described as percents, and groups were compared using chi-square tests. Hospital death is defined as death within 30 days after the procedure or death before discharge, if beyond 30 days. Groups were compared using Fisher's exact tests. Mantel-Haenszel exact tests were used to compare groups while controlling for other factors.

\section{RESULTS}

\section{Comparability of Groups}

There were no significant differences between the groups with regard to age, gender, cause of the aneurysm, connective tissue disorder, history of hypertension, COPD, urgency, previous cerebrovascular accidents, coronary artery disease, renal function, or history of smoking. Table 1 


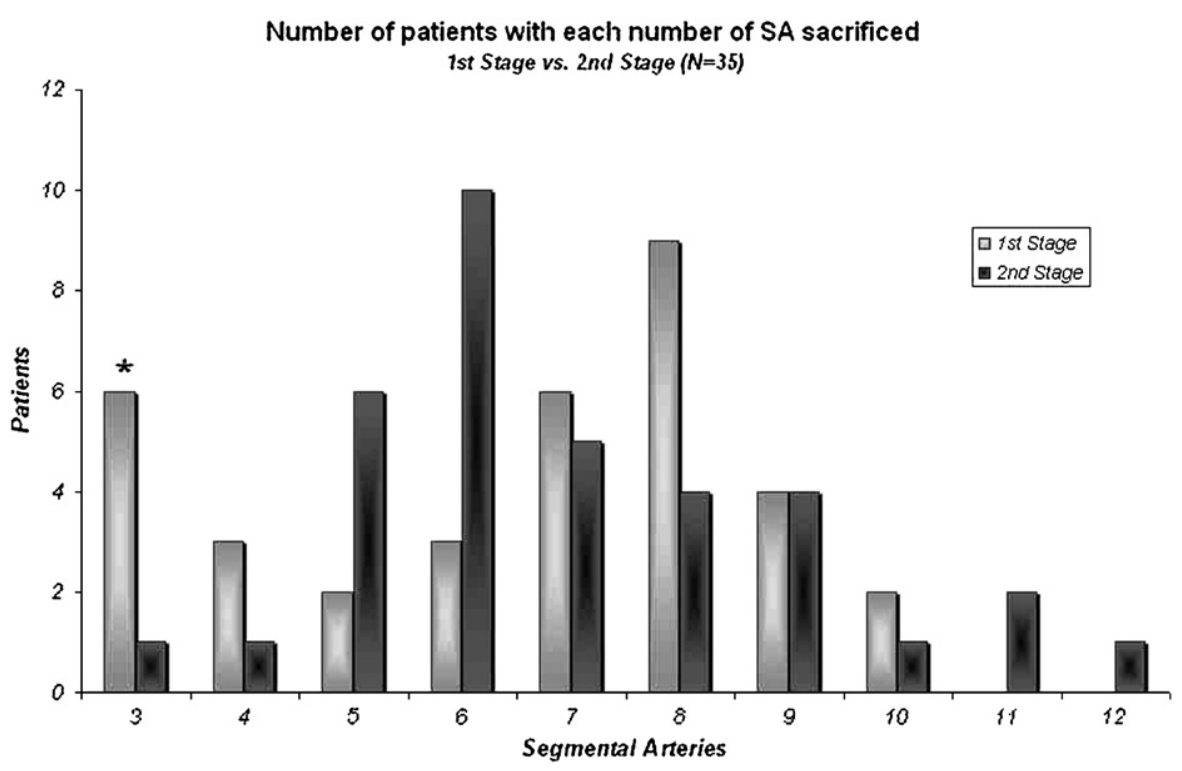

FIGURE 3. The number of patients with each number of segmental arteries sacrificed during the first and second stages $(N=35)$. Six patients $(*)$ had an abdominal aortic aneurysm repair as the first stage. $S A$, Segmental artery.

summarizes the clinical characteristics of all patients. The year of the procedure was not associated with a preference for any group.

Single-stage repairs were slightly more likely to be carried out under HCA; $4(11 \%)$ of the 2 -stage repairs and 16 $(29 \%)$ of the single-stage repairs had HCA $(P=.07)$. Patients with diabetes or with previous myocardial infarction were less likely to have a 2-stage repair, but the differences were not statistically significant. SSEPs were monitored in all patients, and MEPs were monitored in $39 \%$ of patients; there were no statistically significant differences between groups $(P=1)$. CSF was drained in $84 \%$ with no statistically significant difference between single-stage versus 2 stage groups $(P=.77$; Table 2$)$.

There was no significant difference in the number of patients who required visceral artery reimplantation $(P=.29)$; some patients had an anastomosis beveled so that visceral artery implantation was not required even though SA sacrifice was extensive. A greater number of segmental arteries were ultimately sacrificed in the 2-stage group (median, 14; range, 11-15) compared with the single-stage group (median, 12; range, $9-15 ; P<.0001)$.

\section{Complications and Mortality}

Overall hospital mortality was $11.1 \%$ (10/90), with no difference between single-stage procedures $(6 / 55 ; 10.9 \%)$ compared with the second operation in the 2-stage group $(4 / 35 ; 11.4 \% ; P=1)$. There were no statistically significant differences in stroke $(P=1)$, postoperative bleeding $(P=.15)$, renal failure $(P=1)$, or pulmonary insufficiency $(P=.1)$ between the groups. Table 3 summarizes the postoperative course and complications for the 2 groups.

\section{Spinal Cord Injury}

The risk of paraplegia or paraparesis, however, differed significantly between the groups: Fifteen percent $(8 / 55$; Figure 1) in the single-stage group had permanent spinal cord injury versus none in the 2-stage group $(0 / 35$, $P=.02)$. The significantly lower rate of paraplegia and paraparesis in the 2-stage group occurred despite a significantly higher number of SAs sacrificed in this group: a median of $14(11-15)$ versus $12(9-15)(P<.0001)$. The significant difference between single- and 2-stage procedures in the incidence of paraplegia persisted when controlling (one at a time) for diabetes, coronary artery disease, and repair under HCA.

\section{Single-Stage Repairs With and Without Hypothermic Circulatory Arrest}

Spinal cord injury seemed more likely to develop in patients undergoing a single-stage repair without HCA than with HCA $(7 / 39=18 \%$ vs $1 / 16=6 \%)$. The number of patients, however, was too small to enable statistical analysis.

\section{DISCUSSION}

This retrospective review of our experience suggests that paraplegia after open repair of extensive TAA/A may occur significantly less frequently when the repair is carried out in 2 stages rather than a single procedure. The absence of paraplegia in the 2-stage repair group occurred even though the total number of SAs sacrificed was greater with 2-stage repairs than with single-stage procedures, which would engender an expectation of a higher incidence of paraplegia or paraparesis after 2-stage repair. Although this observation 
TABLE 3. Postoperative course, complications, and outcomes

\begin{tabular}{|c|c|c|c|c|}
\hline & $\begin{array}{c}\text { All } \\
\mathbf{N}=\mathbf{9 0}\end{array}$ & $\begin{array}{c}\text { Single-stage } \\
\text { procedure } \\
\mathbf{N}=\mathbf{5 5}\end{array}$ & $\begin{array}{c}\text { 2-stage } \\
\text { procedure } \\
\mathbf{N}=35\end{array}$ & $\begin{array}{c}P \\
\text { value* }\end{array}$ \\
\hline Hospital mortality & $10(11 \%)$ & $6(11 \%)$ & $4(11 \%)$ & 1 \\
\hline $\begin{array}{c}\text { Spinal cord } \\
\text { injury } \dagger\end{array}$ & $8(9 \%)$ & $8(15 \%)$ & 0 & .02 \\
\hline Stroke & $4(4 \%)$ & $3(5 \%)$ & $1(3 \%)$ & 1 \\
\hline $\begin{array}{l}\text { Bleeding requiring } \\
\text { reoperation }\end{array}$ & $2(2 \%)$ & 0 & $2(6 \%)$ & .15 \\
\hline Renal insufficiency & $11(12 \%)$ & $7(13 \%)$ & $4(11 \%)$ & 1 \\
\hline Temporary dialysis $\ddagger$ & $4(4 \%)$ & $2(4 \%)$ & $2(6 \%)$ & \\
\hline Permanent dialysis & $7(8 \%)$ & $5(9 \%)$ & $2(6 \%)$ & \\
\hline Respiratory complications & $19(21 \%)$ & $12(22 \%)$ & $7(20 \%)$ & 1 \\
\hline Tracheotomy & $18(20 \%)$ & $12(22 \%)$ & $6(17 \%)$ & \\
\hline $\mathrm{ECMO} \S$ & $1(1 \%)$ & - & $1(3 \%)$ & \\
\hline Cardiac complications & $3(3 \%)$ & $1(2 \%)$ & $2(6 \%)$ & .56 \\
\hline Cardiac arrest & $2(2 \%)$ & $1(2 \%)$ & $1(3 \%)$ & \\
\hline $\begin{array}{l}\text { Permanent pacemaker } \\
\text { insertion }\end{array}$ & $1(1 \%)$ & - & $1(3 \%)$ & \\
\hline ICU\| stay (d) & & & & .36 \\
\hline Mean \pm SD & $5.1 \pm 5.6$ & $6 \pm 6.8$ & $3.7 \pm 2.2$ & \\
\hline Median (range) & $3(1-33)$ & $3(2-33)$ & $3(1-9)$ & \\
\hline Hospital stay (d) & & & & .15 \\
\hline Mean \pm SD & $23.3 \pm 21$ & $27.3 \pm 24.4$ & $16.8 \pm 11.5$ & \\
\hline Median (range) & $15(1-95)$ & $16(8-95)$ & $13.5(1-58)$ & \\
\hline Adverse outcome $\|$ & $22(24 \%)$ & $15(27 \%)$ & $7(20 \%)$ & .46 \\
\hline \multicolumn{5}{|c|}{$\begin{array}{l}\text { ECMO, Extracorporeal membrane oxygenation; } I C U \text {, intensive care unit; } S D \text {, standard } \\
\text { deviation. *Based on the Kruskal-Wallis or Fisher's exact test. } \dagger \text { Paraplegia or parapa- } \\
\text { resis. †Patients did not require further dialysis after discharge. } \S \text { Extracorporeal mem- } \\
\text { brane oxygenation. } \| \text { Adverse outcome }=\text { in-hospital death, spinal cord injury, stroke, } \\
\text { or permanent dialysis. Two-stage data reflect only the second of the } 2 \text {-stage proce- } \\
\text { dures. }\end{array}$} \\
\hline
\end{tabular}

is far from definitively establishing that dividing an extensive aneurysm resection into 2 stages may be helpful in preventing paraplegia, there is reason to believe that this may be a promising approach.

The significantly lower rate of spinal cord injury after 2stage repair of extensive thoracoabdominal aneurysms compared with the rate after repair of aneurysms of comparable or even slightly lesser size in a single stage can be explained by considering what is known about what happens to the spinal cord circulation after serial surgical sacrifice of most or all of the SAs in an experimental model. The perfusion of the spinal cord subsequently depends on the stabilization of a collateral network that includes the paraspinous muscles, has extensive interconnections with the nutrient arteries of the spinal cord, and is fed from below by the hypogastric arteries and from above by the internal thoracic and other branches of the subclavian arteries. Experimental studies have demonstrated that the collateral network undergoes changes after extensive SA sacrifice, with enlargement of its arteriolar capacity and a reorientation of small arteries to allow inflow caudally and cranially to the center of the length of the spinal cord that has been deprived of more direct SA nourishment. Some of the collateral network adaptations are achieved by immediate vasodilatation in response to the demands of spinal cord metabolism, but other changes reflect a remodeling process that takes time. The interval between the stages of a 2-stage repair allows stable remodeling of the inflow to whatever portion of the spinal cord is affected by SA sacrifice during the first procedure before the collateral network is called on to provide enhanced inflow after the sacrifice of the remaining SAs during the second stage.

An estimate of the time course of the adaptation of the collateral network that provides spinal cord blood flow when SAs are sacrificed can be obtained by monitoring the pressure in the distal stump of a single SA in the middle of the length of spinal cord affected by SA sacrifice. ${ }^{19}$ If one does serial measurements of this pressure, which we consider the spinal cord perfusion pressure and have followed in a few patients and several experimental animals, one can see that the spinal cord perfusion pressure falls to low levels after extensive SA sacrifice, reaching a nadir several hours postoperatively. ${ }^{20}$ Recovery of the pressure to approximately $60 \%$ of preoperative levels occurs by 48 hours and appears complete by approximately 5 days. ${ }^{20}$ Because experimental observations show substantial remodeling of the collateral arteriolar network several days after extensive SA sacrifice, the collateral blood supply should be robust by the time of a second operation after initial aneurysm repair in almost all instances, making the sacrifice of any remaining SAs less of a threat to spinal cord viability than if all the involved SAs are sacrificed at one time.

It is true that the patients who underwent 2-stage procedures in this series were not a homogeneous group with an anticipated 2-stage strategy, but rather had clinically relevant aneurysms in different parts of the aorta requiring intervention at different times. Some of the patients with singlestage procedures, however, could conceivably have had their single-stage operations performed in 2 stages, with 1 of them possibly an endovascular procedure, if this were a proven means of eliminating the threat of paraplegia. The apparently negligible risk of paraplegia with 2-stage procedures found in this retrospective review suggests that dividing an extensive resection into stages may be an effective strategy if it is anatomically feasible and the risk of rupture between the stages is judged to be modest. Previous studies of 2-stage versus single-stage procedures in the ascending aorta, aortic arch, and proximal descending aorta have shown a high combined morbidity and mortality resulting from the 2-stage approach, especially when interim mortality from rupture is taken into account. ${ }^{21-24}$ But the promise of significantly lower paraplegia rates, as well as possibly lower overall morbidity with hybrid procedures, suggests that a 2-stage approach to the descending and thoracoabdominal aorta may be worth considering.

We recognize that this retrospective study has definite limitations. Because none of the staged patients underwent intentional, planned 2-stage repair, a selection bias is hard 
to exclude. Selection bias may explain why patients with diabetes and previous myocardial infarction were somewhat less likely to have undergone a 2-stage procedure rather than a single-stage procedure, although this difference was not statistically significant and other patient risk factors seem comparable. All patients had relatively long intervals between the 2 procedures that would likely exceed the usual recommendation for a planned 2-stage approach, ${ }^{21,24}$ which may have resulted in exclusion of patients with large aneurysms prone to rupture and those with serious comorbid conditions. Furthermore, the long interval between operations may have enhanced the stability of the spinal cord circulatory adaptations after the first repair, and therefore improved spinal cord recovery after the second stage.

All patients included in the 2-stage group must, by definition, have survived the first stage of the procedure. We have only incomplete data from the initial operations, some of which were performed at other institutions. For patients at our institution with aneurysms of comparable extent as those resected in the first operation of the 2-stage group, we encountered a mortality of $6 \%$ and no paraplegia. (In our experience, using spinal cord protection measures including SSEP/MEP monitoring and CSF drainage, no spinal cord injury occurred in any elective aneurysm repair in which $<11$ SAs were resected. ${ }^{25}$ ) If we try to reconstruct the true mortality of the 2-stage approach by adding the anticipated deaths from the first procedure $(\mathrm{N}=2)$ to the documented mortality after the second procedure $(\mathrm{N}=4)$, we arrive at an estimated combined mortality only slightly higher than for a single-stage operation ( $16 \%$ vs $11 \%)$, but by taking into account the high 1-year mortality among patients with postoperative spinal cord injury, this difference in early mortality is likely negligible. This makes a 2-stage approach still an appealing alternative if it removes the threat of paraplegia.

Before considering these observations an endorsement of a planned hybrid 2-stage approach, with an endovascular component, in patients in whom a single-stage open procedure could be performed, one must also ask whether sudden occlusion of SAs with a graft is equivalent to more gradual serial SA sacrifice. From what has been published, endovascular repair does not seem to be associated with dramatically higher paraplegia rates than open surgical repair, but a direct experimental comparison could serve to answer this question more clearly. It would seem prudent to use the precautions developed by surgeons to protect the spinal cord from intraprocedural injury during endovascular repair as well: reduction of metabolic rate using hypothermia and monitoring of MEPs and SSEPs. With regard to adjuncts, it should be noted that the use of HCA was associated with a lower rate of paraplegia after single-stage repair in this series.

With current technology, the most appealing scenario for a planned 2-stage approach is a hybrid procedure with an endovascular second stage. This would allow one to avoid confronting the daunting challenges of a second open operation, with its increased risk of bleeding and pulmonary injury. An attractive option would be to replace the visceral segment of the abdominal aorta during an initial open procedure, followed by endovascular stenting of the entire descending thoracic aorta. There would be no need for a separate debranching operation, and one could leave an access graft in place after the initial procedure to facilitate subsequent thoracic stent placement.

Because the 2-stage group did not have both procedures planned in advance, the question of what is an ideal time between procedures could not be addressed in this study, but it is of obvious importance when contemplating a deliberate 2stage strategy. Further experimental work will be required to provide a definitive answer, but preliminary studies suggest that the collateral circulation is able to restore flow to the spinal cord 5 to 7 days after SA ligation. This short recovery time makes the deliberate choice of a 2-stage approach potentially appealing as a clinical strategy, because the patient could be kept under close surveillance during the interval between procedures, minimizing the risk of rupture.

\section{CONCLUSIONS}

A staged approach to extensive TAA-A repair may reduce the incidence of spinal cord injury. This is of potential importance in designing strategies involving hybrid or entirely endovascular procedures. If a staged approach is not possible, a single-stage procedure using HCA seems to protect the spinal cord better than a single-stage procedure using other perfusion techniques.

\section{References}

1. Coselli JS, LeMaire SA, Conklin LD, Koksoy C, Schmittling ZC. Morbidity and mortality after extent II thoracoabdominal aortic aneurysm repair. Ann Thorac Surg. 2002;73:1107-15; discussion 1115-6.

2. Coselli JS, Conklin LD, LeMaire SA. Thoracoabdominal aortic aneurysm repair: review and update of current strategies. Ann Thorac Surg. 2002;74:S1881-4; discussion S1892-8.

3. Etz CD, Halstead JC, Spielvogel D, Shahani R, Lazala R, Homann TM, et al. Thoracic and thoracoabdominal aneurysm repair: is reimplantation of spinal cord arteries a waste of time? Ann Thorac Surg. 2006;82:1670-7.

4. Coselli JS, LeMaire SA, Miller CC 3rd, Schmittling ZC, Koksoy C, Pagan J, et al. Mortality and paraplegia after thoracoabdominal aortic aneurysm repair: a risk factor analysis. Ann Thorac Surg. 2000;69:409-14.

5. Griepp RB, Griepp EB. Spinal cord perfusion and protection during descending thoracic and thoracoabdominal aortic surgery: the collateral network concept. Ann Thorac Surg. 2007;83:S865-9; discussion S890-2.

6. Conrad MF, Crawford RS, Davison JK, Cambria RP. Thoracoabdominal aneurysm repair: a 20-year perspective. Ann Thorac Surg. 2007;83:S856-61; discussion $\mathrm{S} 890-\mathrm{S} 2$.

7. Roselli EE, Greenberg RK, Pfaff K, Francis C, Svensson LG, Lytle BW. Endovascular treatment of thoracoabdominal aortic aneurysms. J Thorac Cardiovasc Surg. 2007;133:1474-82.

8. Coselli JS, Lemaire SA, Koksoy C, Schmittling ZC, Curling PE. Cerebrospinal fluid drainage reduces paraplegia after thoracoabdominal aortic aneurysm repair: results of a randomized clinical trial. Vasc Surg. 2002;35:631-9.

9. Kouchoukos NT, Masetti P, Rokkas CK, Murphy SF. Hypothermic cardiopulmonary bypass and circulatory arrest for operations on the descending thoracic and thoracoabdominal aorta. Ann Thorac Surg. 2002;74:S1885-7; discussion S1892-8. 
10. Safi HJ, Miller CC 3rd. Spinal cord protection in descending thoracic and thoracoabdominal aortic repair. Ann Thorac Surg. 1999;67:1937-9; discussion 1953-8.

11. Cambria RP, Davison JK, Carter C, Brewster DC, Chang Y, Clark KA, et al. Epidural cooling for spinal cord protection during thoracoabdominal aneurysm repair: a five-year experience. J Vasc Surg. 2000;31:1093-102.

12. Estrera AL, Miller CC 3rd, Huynh TT, Porat E, Safi HJ. Neurologic outcome after thoracic and thoracoabdominal aortic aneurysm repair. Ann Thorac Surg. 2001; 72:1225-31.

13. Schepens M, Dossche K, Morshuis W, Heijmen R, van Dongen E, Ter Beek H, et al. Introduction of adjuncts and their influence on changing results in 402 consecutive thoracoabdominal aortic aneurysm repairs. Eur J Cardiothorac Surg. 2004;25:701-7.

14. Jacobs MJ, Mess W, Mochtar B, Nijenhuis RJ, Statius van Eps RG, Schurink GW. The value of motor evoked potentials in reducing paraplegia during thoracoabdominal aneurysm repair. J Vasc Surg. 2006;43:239-46.

15. Svensson LG, Hess KR, D'Agostino RS, Entrup MH, Hreib K, Kimmel WA, et al. Reduction of neurologic injury after high-risk thoracoabdominal aortic operation. Ann Thorac Surg. 1998;66:132-8.

16. Galla JD, Ergin MA, Lansman SL, McCullough JN, Nguyen KH, Spielvogel D, et al. Use of somatosensory evoked potentials for thoracic and thoracoabdominal aortic resections. Ann Thorac Surg. 1999;67:1947-58.

17. Etz CD, Di Luozzo G, Bello R, Luehr M, Khan MZ, Bodian CA, et al. Pulmonary complications after descending thoracic and thoracoabdominal aortic aneurysm repair: predictors, prevention, and treatment. Ann Thorac Surg. 2007;83: S870-6; discussion S890-2.

18. Strauch JT, Spielvogel D, Lauten A, Lansman SL, McMurtry K, Bodian CA, et al. Axillary artery cannulation: routine use in ascending aorta and aortic arch replacement. Ann Thorac Surg. 2004;78:103-8.

19. Etz CD, Di Luozzo G, Zoli S, Lazala R, Plestis KA, Bodian CA, et al. Direct spinal cord perfusion pressure monitoring in extensive distal aortic aneurysm repair. Ann Thorac Surg. 2009;87:1764-74.

20. Etz CD, Homann TM, Plestis KA, Zhang N, Luehr M, Weisz DJ, et al. Spinal cord perfusion after extensive segmental artery sacrifice: can paraplegia be prevented? Eur J Cardiothorac Surg. 2007;31:643-8.

21. Etz CD, Plestis KA, Kari FA, Luehr M, Bodian CA, Spielvogel D, et al. Staged repair of thoracic and thoracoabdominal aortic aneurysms using the elephant trunk technique: a consecutive series of 215 first stage and 120 complete repairs. Eur J Cardiothorac Surg. 2008;34:605-15. Epub 2008 Jun 13.

22. Coselli JS, LeMaire SA, Carter SA, Conklin LD. The reversed elephant trunk technique used for treatment of complex aneurysms of the entire thoracic aorta. Ann Thorac Surg. 2005;80:2166-72.

23. Safi HJ, Miller CC 3rd, Estrera AL, Huynh TT, Rubenstein FS, Subramaniam MH, et al. Staged repair of extensive aortic aneurysms: morbidity and mortality in the elephant trunk technique. Circulation. 2001;104:2938-42.

24. Safi HJ, Miller CC 3rd, Estrera AL, Huynh TT, Porat EE, Allen BS, et al. Staged repair of extensive aortic aneurysms: long-term experience with the elephant trunk technique. Ann Surg. 2004;240:677-84; discussion 684-5.

25. Griepp RB, Ergin MA, Galla JD, Lansman S, Khan N, Quintana C, et al. Looking for the artery of Adamkiewicz: a quest to minimize paraplegia after operations for aneurysms of the descending thoracic and thoracoabdominal aorta. J Thorac Cardiovasc Surg. 1996;112:1202-13; discussion 1213-205.

\section{Discussion}

Dr Joseph Coselli (Houston, Tex). Dr Etz, congratulations. The Mount Sinai group once again, with tenacity and focus, raises the provocative issue that spinal cord injury after thoracoabdominal aortic aneurysm resection is not affected after extensive SA sacrifice. By evaluating 90 patients retrospectively, they compare 55 patients with Crawford extent II aneurysms repaired in a single-stage procedure with 35 patients with aneurysms repaired in 2 separate operations. Mortality $(\sim 11 \%)$ was no different between the 2 groups; however, the occurrence of paraplegia was approximately $15 \%$ in the former cohort and none in the latter cohort. The results and their strategy are outstanding.

In our own work, we have reported on 762 extent II thoracoabdominal aortic aneurysms with an intercostal artery reattachment strategy and a $6.3 \%$ spinal cord injury rate. Separately, in 1997 , we reported on the impact of previous thoracic aortic repair on thoracoabdominal aortic aneurysm management comparing groups similar to the authors' groups. In the Crawford extent II group with a single-stage procedure, 143 patients had a $13.9 \%$ paraplegia rate versus only $3 \%$ for 66 patients repaired in a staged fashion, essentially confirming what the authors find here.

In 118 patients with extent III and IV aneurysms, we encountered paraplegia and paraparesis rates of $2.5 \%$ and $1 \%$, respectively. Thus, the overall risk of paraplegia when staged to 2 separate operations is significantly affected by the first operation. The authors deal with this by extrapolating from their own work but use patients in need of limited aortic resection rather than extent II aneurysms, based on the article.

Curiously, if all the patients were categorized as Crawford extent II in this series, one would expect the same number of intercostal arteries would have been eliminated in both groups at the end of the day. But what you found was a significant difference, a median of 14 versus $12(P<.0001)$. Many of the first-stage procedures were carried out at another institution and the number of segmental arteries reattached is not really known, and with the small sample size I believe this remains an important concern. My questions are quick.

Barring a prospective randomized trial, do the authors think that it would be more relevant to evaluate only their own cases and use an intention-to-treat analysis? For patients who are anatomically unable to undergo a concomitant procedure (ie, a hybrid endovascular procedure), how do the authors approach their current patients, staged or single operation in Crawford extent II aneurysms?

Dr Etz. There are definite limitations, as you mentioned, to this study. It is retrospective, in the first place. In this 2-stage group there was no intention to treat these patients in a 2-stage fashion, but they just came back for the extending aneurysm after a couple of years. So your suggestion definitely is valid, and it would be a good idea to do this in a randomized prospective fashion, although we believe there is experimental evidence, and from this retrospective study some clinical evidence, that it may not be necessary, but we just proceed, if we can, with a 2-stage procedure, which takes me to the second question.

If a patient cannot undergo a 2-stage procedure, there is some evidence (and I don't know whether I can show my discussion slides here; probably not), if you look in the abstract book at this graph, that if you have to repair a Crawford type II aneurysm in a single stage, it may be better to do this under HCA or with HCA. In the group we analyzed, in these 55 patients, there were 16 patients who had HCA with only 1 patient ending up paraplegic, whereas there were 7 cases of paraplegia in the remaining 39 patients who underwent this single-stage Crawford type II aneurysm repair with various other perfusion techniques. Unfortunately, the numbers are not powerful enough to prove this hypothesis, but this is probably what we would do in the future, and we are about to work on further analysis to prove this with larger numbers.

Dr Joseph Bavaria (Philadelphia, $\mathrm{Pa}$ ). This is intriguing, and I suppose it is based on your theories that the collateral network will come together within a week or with some time. How do you propose we do this? For a patient with a type II thoracic aneurysm, should we do the distal part first and then stent the proximal part? Should we do the proximal part first and then the distal part 
open? Should we do the distal part first and then stent the proximal part? What is the interval? What do you think the problems are going to be when sewing grafts to $56-\mathrm{cm}$ aortas? Do we use a Dumbo graft as a diaphragm like we do with a Dumbo elephant trunk? What is your proposition?

Dr Etz. To answer the first question in terms of what should be done first. Should we do the descending part first or the lumbar part first if a patient has a type II aneurysm. At this point, there is no clear evidence as to what is better. We are currently working on this question in the laboratory. It probably would depend on technical issues of where you think you can get a proper landing zone first and whether you can put a descending graft in an elephant trunk-like fashion and then stent. Another possibility would be to do a debranching-like procedure or replace the lumbar part first, and then not having to deal with the debranching anymore, just stent the descending thoracic. At this point, there is no evidence and probably a couple of good solutions coming up in the future.

Dr John Fehrenbacher (Indianapolis, Ind). I guess I would have drawn different conclusions from your article than you did. We have operated on approximately 300 thoracoabdominal aneurysms, and I think well more than 50 of these are Crawford IIs, using deep HCA. We have an overall low paraplegia rate $(<5 \%)$, but we also implant intercostal arteries. My approach would not change after hearing your presentation, but to the contrary, I think it supports intercostal reimplantation. Therefore, my conclusions from your presentation would be in resection of extensive thoracoabdominal aneurysms, one should reimplant intercostal arteries.

Dr Etz. There is certainly nothing wrong with reimplanting segmental arteries if that is technically feasible and you do it under cir- culatory arrest, but the work we are presenting here is thought to pave the way for hybrid and totally endovascular procedures, and then this is obviously no option. So that would be the answer.

Dr Frank Baciewicz (Detroit, Mich). You may have already answered this question, but the mean interval between the 2 operations was 5 years. Did you find any difference in the paraplegia rate if the time interval was short or long? I would expect the longer the time interval the greater chance for a collateral development and less paraplegia.

Dr Etz. In this cohort there were only 35 patients and no case of paraplegia, so there was no chance to analyze the interval in terms of its association with paraplegia rate. From the experimental work we know that after you measure the pressure in the stump of the sacrificed SA, the pressure completely recovers to the pre-sacrifice level within 5 days. The same applies to the spinal cord blood flow that we could measure in the laboratory setting with fluorescent microspheres, and it tells us exactly what the flow is, and the restoration of course is also within 5 days. So obviously we believe that a similar dynamic also applies in the human setting. Certainly it seems clear that if you give a little more time you will probably get a better remodeling, but that will stop at some point.

Dr Lars Svensson (Cleveland, Ohio). With descending stents readily available and the delay in getting thoracoabdominal stent grafts, which, unfortunately, take approximately 3 months to build, what we have been doing in a number of patients is what you are suggesting, in other words, stent the descending aorta or elephant trunk and then come back later and do the thoracoabdominal stenting. We believe this also has reduced the incidence of paralysis, particularly in the type IIs with thoracoabdominal stenting. 